\title{
Effectiveness of Premedication with Analgesics vs Placebo for Success of Inferior Alveolar Nerve Block in Irreversible Pulpitis
}

\author{
Aisha Wali, Talha Mufeed Siddiqui, Nauman Qamar, Rabia Khan, Nausheen Jawaid
}

\begin{abstract}
Pain is considered to be the major cause for seeking emergency endodontic treatment. Pain management is of vital importance in endodontics with no exception. Local anesthesia is considered to be the primary method to control pain. An effective local anesthesia cannot be obtained if pulp is inflamed. Clinician prescribes nonsteroidal anti-inflammatory drugs (NSAIDs) as premedication on a routine basis for mild to moderate pain to reduce pulpal inflammation before injecting anesthesia. These drugs are beneficial in providing relief from pain and inflammation in irreversible pulpitis and helps in providing effectiveness of inferior alveolar nerve block. Moreover, they have a short half life, which would make them ideal for a single dosage prior to the management of severe pain.
\end{abstract}

Aim: To conduct a randomized- placebo controlled clinical trial to compare the effectiveness of premedication with analgesics vs placebo for success of inferior alveolar nerve block in irreversible pulpitis.

Materials and methods: The study consisted of 80 adult patients attending operative Outpatient Department in Baqai Dental College. Informed Consent was obtained from each participant. Subjects were randomly divided in four groups comprising of 20 subjects in each group. Group A received piroxicam (Feldene $20 \mathrm{mg}$, P fizer), group $B$ received diclofenac potassium (Fastaid Plus, $50 \mathrm{mg}$ platinum pharmaceutic), group $C$ received naproxen sodium (Synflex $550 \mathrm{mg}, \mathrm{ICl}$ ), and group $D$ received a placebo drug becefol (Abbott). Medication was given 1 hour before initiating endodontic treatment. After 1 hour of oral administration of tablets, inferior alveolar nerve block using $1.8 \mathrm{ml}$ of $2 \%$ lidocaine containing $1: 200,000$ epinephrine was given. After 15 minutes, access cavity preparation was initiated and patients were asked to inform if they experienced pain. Patients were excluded from the study if they experienced pain but if the patient did not feel pain endodontic treatment was continued. $p$-value was set at 0.05 . Data was analyzed by using Chi-square test (SPSS 19).

Results: The result showed that out of 80 patients who participated in the study, success rate for piroxicam came out to $90 \%$ (10 male and 8 female patients), followed by diclofenac potassium with $75 \%$ success rate ( 9 male and 6 female patients), naproxen sodium with $35 \%$ success rate $(3$ male and 4 female patients) and placebo with 10\% success (1 male and 1 female patient).

Conclusion: The current study concludes that premedication given 1 hour before injecting anesthesia is helpful in reducing pain intensity and thus causing inferior alveolar nerve block to be effective.

Keywords: Preoperative NSAIDs, Diclofenac potassium, Naproxen sodium, Piroxicam, Premedication.

How to cite this article: Wali A, Siddiqui TM, Q amar N, Khan R, J awaid N. Effectiveness of Premedication with Analgesics vs
Placebo for Success of Inferior Alveolar Nerve B lock in Irreversible Pulpitis. Int J Prosthodont Restor Dent 2012;2(1):5-9.

\section{Source of support: Nil}

\section{Conflict of interest: None}

\section{INTRODUCTION}

The current definition of pain as described by the International Association for the Study of Pain is an unpleasant sensory and emotional experience associated with actual or potential tissue damage. ${ }^{1}$ Pain is considered to be the major cause for seeking emergency endodontic treatment. ${ }^{2}$ Segal ${ }^{3}$ reported that $66 \%$ of patients in pain require emergency endodontic treatment, $89 \%$ of them had been in pain for more than a week. $0^{\prime} \mathrm{K}$ eefe ${ }^{2}$ reported that $62 \%$ of patients in moderate to severe pain require emergency treatment. Seltzer et al ${ }^{4}$ and others ${ }^{5,6}$ have show $n$ that pulp vitality is not only determined by considering the pain symptoms. Proper pain history, clinical examination and vitality tests are the main diagnostic elements.

Pain management is of vital importance in endodontics with no exception. Local anesthesia is considered to be the primary method to control pain. A n effective local anesthesia cannot be obtained if pulp is inflamed. ${ }^{7}$ Inferior alveolar nerve block is considered as one of the most technically difficult local anesthetic injections. In the absence of pulpal inflammation, inferior al veolar nerve block provides 85 to $90 \%$ clinically effective anesthesia. ${ }^{8-11}$ In cases of irreversible pulpitis, the rate of success is greatly reduced (as low as 20\%). Previous studies have cited several reasons for the failure of inferior alveolar nerve block. These include anatomical variations, acute tachyphylaxis, effect of inflammation on local tissue $\mathrm{pH}$, blood flow, nociceptors and central sensitization and psychological factors. ${ }^{12}$ Several published articles about failure of local anesthesia concluded that inferior alveolar nerve blocks are the most technically difficult anesthesia with the success rate of 75 to $90 \%$ for uninflammed pulp. ${ }^{13-16} \mathrm{~V}$ arious articles concluded that inferior alveolar nerve block is less effective when pulp is inflammed, with failure rate of 30 to $80 \%$. Several researchers suggested that if pulpal inflammation can be reduced before injecting anesthesia, inferior alveolar nerve block might be more effective. $8-10,13,17$ 
Clinicians prescribe nonsteroidal anti-inflammatory drugs (NSAIDS) on a routine basis for mild to moderate pain. ${ }^{18}$ NSAIDs block the cyclooxygenase enzyme in the pathway that produces prostaglandins, resulting in lower levels of inflammation. ${ }^{19,20} \mathrm{M}$ ultiple study results showed that NSAIDs used as premedication reduces pain and inflammation. ${ }^{21-23}$ O ne study concluded that acetaminophen with codeine or ibuprofen improved the efficacy of inferior alveolar nerve block, ${ }^{24}$ while another study showed that neither ibuprofen nor ketorolac caused any improvement. ${ }^{25}$ Diclofenac is a benzoic acid derivative available as diclofenac sodium and diclofenac potassium, with sodium salt used more frequently. ${ }^{26}$ Diclofenac potassium is considered the most preferable drug of choice for moderate to severe pain as it significantly reduces pain within 15 to 30 minutes. ${ }^{27}$ Piroxicam is a potent inhibitor of cyclooxygenase step of arachidonic acid metabolism. ${ }^{28}$ Comparison of PG biosynthesis inhibitory activity of piroxicam with other NSA ID s marks piroxicam as the most effective drug in pulpitis. ${ }^{29}$ Naproxen is an NSA ID that inhibits the cyclooxygenase pathway, thus preventing the release of inflammatory mediators, such as prostaglandins. ${ }^{30}$ These drugs are beneficial in providing relief of pain and inflammation in irreversible pulpitis and helps in providing effectiveness of inferior alveolar nerve block. Moreover, they have a short half-life, which would make them ideal for a single dosage prior to the management of severe pain. ${ }^{26,31,32}$

\section{MATERIALS AND METHODS}

\section{Patient Selection and Operator}

The study consisted of 80 adult patients attending 0 utpatient Department, O perative Dentistry, B aqai Dental College (Fig. 1). Healthy patients who experienced pain in mandibular molars that responded to cold application for 30 to 45 seconds were included. The exclusion criteria included the following conditions: (1) Patients allergic to NSA IDs, (2) alcoholics or smokers, (3) history of peptic ulcer, (4) history of bleeding problems, or (5) anticoagulant use and (6) pregnant or breastfeeding. Teeth with necrotic pulp, acute apical abscess, cellulitis, vertical fractures were also excluded from the study. Ethical approval of the study was obtained from the Ethical Commitee, Baqai M edical University. Informed consent was also obtained from each participant. Subjects were randomly divided into four groups comprising 20 subjects in each group. Group A received piroxicam (Feldene $20 \mathrm{mg}$, Pfizer), group $B$ received

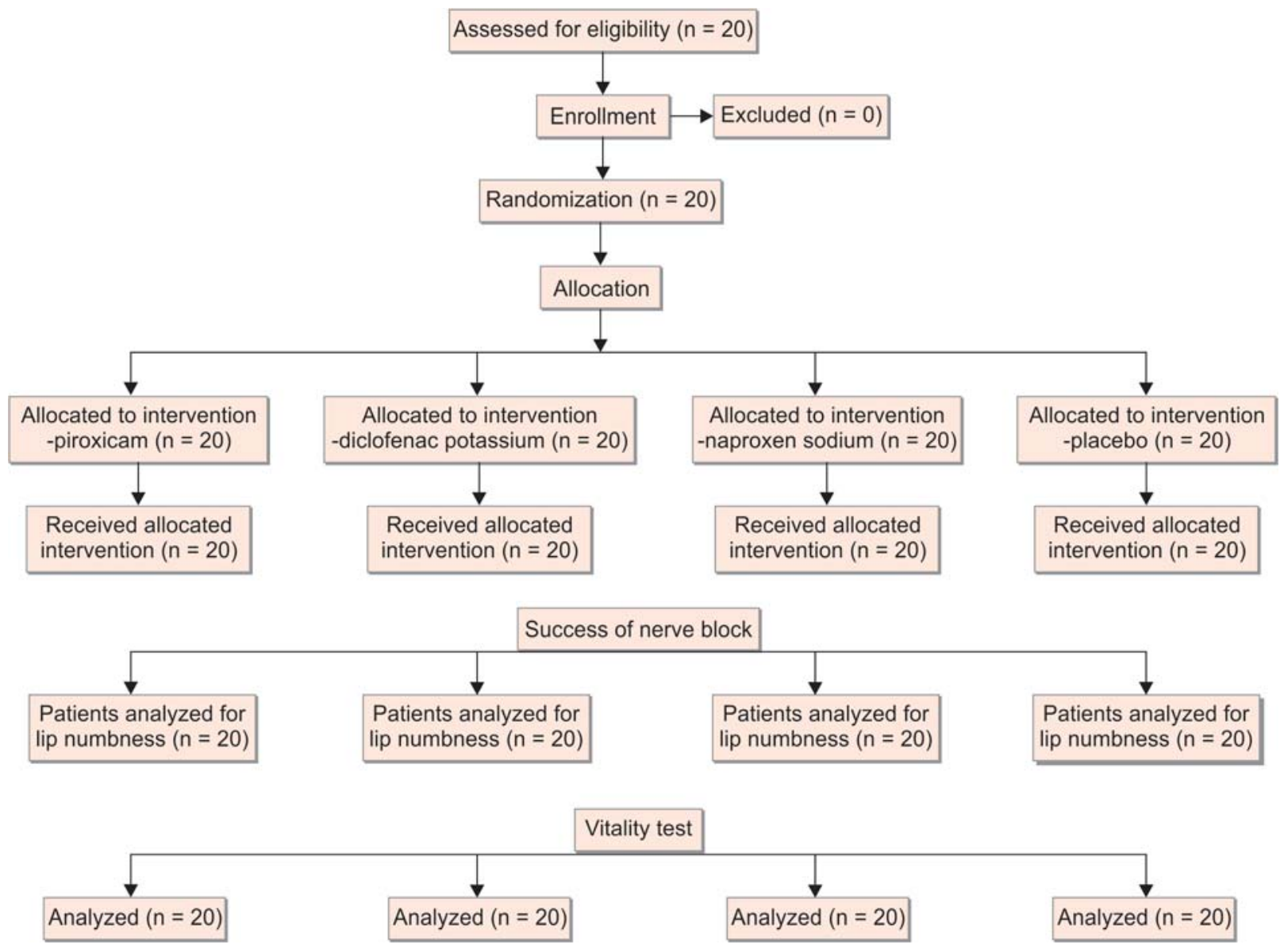

Fig. 1: Consort flow chart 
diclofenac potassium (Fastaid Plus, $50 \mathrm{mg}$ platinum pharmaceutic), group C-received naproxen sodium (Synflex $550 \mathrm{mg}, \mathrm{ICl}$ ) and group $D$ received a placebo drug becefol (A bbott). M edication was given 1 hour before initiating endodontic treatment. After 1 hour of oral administration of tablets, inferior alveolar nerve block using $1.8 \mathrm{ml}$ of $2 \%$ lidocaine containing 1: 200,000 epinephrine was given. A fter 15 minutes, access opening was initiated and patients were asked to inform if they experienced pain. Patients were excluded from the study if they experienced pain but if the patient does not feel pain endodontic treatment was continued. A II patients included in the study had profound lip anesthesia after 15 minutes. Patients reported a significant decrease in pain intensity after injecting local anesthesia. p-value was set at 0.05 . Data was statistically analyzed by Chi- square test using SPSS 19 version.

\section{RESULTS}

Eighty patients participated in the randomized placebo controlled study conducted in the D epartment of O perative Dentistry, Baqai Dental College. Table 1 shows the distribution of the subjects. All subjects were randomly divided into four groups and each group was assigned a drug for premedication. Table 2 shows distribution of drugs. There was a significant difference observed as shown in Table 3, which shows drug efficacy with their $p$-values. The overall success rates for piroxicam came out to be $90 \%$ followed by diclofenac potassium $75 \%$, naproxen sodium $35 \%$ and placebo $10 \%$ (Table 4). Table 5 shows the comparison of drugs with gender.

\begin{tabular}{lll}
\multicolumn{3}{c}{ Table 1: Distribution of the subject } \\
\hline Gender & Male & 42 \\
& Female & 38 \\
\hline
\end{tabular}

\begin{tabular}{lc}
\multicolumn{2}{c}{ Table 2: Distribution of drugs } \\
\hline P remedication & $\mathrm{n}=80$ \\
\hline Piroxicam & 20 \\
Diclofenac potassium & 20 \\
Naproxen sodium & 20 \\
Placebo & 20 \\
\hline
\end{tabular}

Table 3: Comparison of drug efficacy

\begin{tabular}{lccl}
\hline Premedication & Effective & Noneffective & p-value \\
\hline Piroxicam & 18 & 2 & 0.224 \\
Diclofenac potassium & 15 & 5 & 1 \\
Naproxen sodium & 7 & 13 & 0.888 \\
Placebo & 2 & 18 & 0.881 \\
\hline
\end{tabular}

Table 4: Comparison of drug efficacy with gender

\begin{tabular}{lcc}
\hline \multirow{2}{*}{ Premedication } & \multicolumn{2}{c}{ Gender } \\
\cline { 2 - 3 } & Male & Female \\
\hline Piroxicam & 10 & 8 \\
Diclofenac potassium & 9 & 6 \\
Naproxen sodium & 3 & 4 \\
Placebo & 1 & 1 \\
\hline
\end{tabular}

Table 5: Success rates of premedications

\begin{tabular}{lc}
\hline Premedications & Percentage \\
\hline Piroxicam & 90 \\
Diclofenac potassium & 75 \\
Naproxen sodium & 35 \\
Placebo & 10 \\
\hline
\end{tabular}

\section{DISCUSSION}

I rreversible pulpitis is a clinical condition characterized by episodes of sharp shooting pain which lasts from a few minutes up to several hours. In this painful condition, pulp is highly inflammed and often effective anesthesia cannot be obtained. Researchers suggested that an effective local anesthesia can be obtained if the clinician prescribes NSAIDs as a premedication to reduce pulpal inflammation.

The present study was conducted to evaluate the efficacy of the drugs used as premedication. The choice of dicl ofenac potassium, piroxicam, naproxen sodium as premedication in this study came from the fact that these analgesics are fast acting and reduce pain within 15 to 30 minutes. The result of the present study showed that premedication given before 1 hour significantly reduces pain and enhances the success of inferior alveolar nerve block.

Success of inferior alveolar nerve block was significantly greater in patients premedicated with piroxicam (90\%) when compared to naproxen sodium and placebo (35 and 10\% respectively). There were no significant differences reported between piroxicam and diclofenac potassium ( 90 and $75 \%$ ). The difference is not statistically significant in this study and is likely to be a result of the small number of patients. However, the result is clinically significant and this emphasizes the need to include as many subjects as possible.

Lip numbness implies pulpal anesthesia. However, in two clinical trials only 75 and $80 \%$ of the patients with lip numbness had pul pal anesthesia. ${ }^{33}$ In this study lip numbness was achieved in all 80 patients and there was no pain reported during access opening after premedication was given.

Diclofenac potassium, a potent NSAID, has been previously used in a study done by Prasauna et al (2011) as premedication which reported a success rate of $53.5 \%{ }^{34}$ The current study reported success rate of $75 \%$ (15 out of 20 patients). Piroxicam, another NSA ID used in this study, reported a success rate of $90 \%$. This drug is not commonly 
used as premedication, it is recommended for relieving postoperative pain after endodontic therapy or after any surgical procedure, but this clinical trial proved the efficacy of this drug as premedication. Naproxen sodium used as premedication in this clinical trial showed only $35 \%$ ( 7 out of 20 patients) success rate. This drug is primarily used and recommended for reducing postoperative pain because of its delayed onset of absorption. We also used a placebo drug in this clinical trial, which showed that it was effective in only two patients.

\section{CONCLUSION}

The conclusion of the current study was that premedication if given 1 hour before injecting anesthesia is helpful in reducing pain intensity and thus causing inferior alveolar nerve block to be effective.

\section{REFERENCES}

1. IASP Subcommittee on Taxonomy. Pain terms: A list with definitions and notes on usage. Pain 1979;6:249-52.

2. O'K eefe EM . Pain in endodontic therapy: Preliminary study. J Endod 1976:2:315-19.

3. Segal H. Duration and type of emergency patients. Gen Dent 1984;32:507-09.

4. Seltzer S, Bender IB, Zionitz M. The dynamics of pulp inflammation: Correlations between diagnostic data and actual histologic findings in the pulp. Oral Surg Oral M ed Oral Pathol 1963;16:846-71,969-77.

5. Tyldesley WR, M umford J M. Dental pain and the histological condition of the pulp. Dent Pract D ent Rec 1970;10:333-36.

6. Dummer PM , Hicks R, Huws D. Clinical signs and symptoms in pulp disease. Int Endod J 1980;13:27-35.

7. Wallace JA, M ichanowicz AE, M undell RD, Wilson EG. A pilot study of the clinical problem of regionally anesthetizing the pulp of an acutely inflamed mandibular molar. Oral Surg Oral M ed Oral Pathol 1985;59:517-21.

8. Ingle JI, Walton RE, M alamed SF, et al. Preparation for endodontic treatment. In: Ingle JI, B akland LK (Eds). Endodontics (5th ed). Hamilton: BC Decker 2002;385.

9. M alamed SF. M anagement of pain and anxiety. In: Cohen S, B urns R (Eds). Pathways of the pulp (8th ed). St L ouis: M osby, 2002; 735-37.

10. Hargreaves K M, Seltzer S. Pharmacologic control of dental pain. In: Hargreaves KM, Goodis HE (Eds). Seltzer and Bender's dental pulp (3rd ed). Chicago: Quintessence Publishing Co 2002;219

11. Potocnik I, Bajrovic F. Failure of inferior alveolar nerve block in endodontics. Endod Dent Traumatol 1999;15:247-51.

12. Hargreaves K, K eiser K . L ocal anesthetic failures in endodontics: Mechanism and management (a review). Endod Topics 2002;1:26-39.

13. Hargreaves KM. Neurochemical factors in injury and inflammation in orofacial tissues. In: Lavigne G, L und J, Sessle $B$, Dubner R (Eds). Orofacial pain: Basic sciences to clinical management. Chicago: Quintessence 2001;45-52.

14. Jastak J, Y agiela J, Donaldson D. Local anesthetic of the oral cavity. Philadel phia: Sanders 1995:1-339.
15. M alamed S. Handbook of local anesthetic (3rd ed). St L ouis: Mosby 1990:1-332.

16. M illes M. The missed inferior alveolar block: A new look at an old problem. A nesth Prog 1984;31:87-90.

17. Cohen HP, Cha BY, Spangberg LS. Endodontic anesthesia in mandibular molars: A clinical study. J Endod 1993;19:370-73.

18. M ickel AK, Wright AP, Chogle S, Jones JJ, K antorovich I, Curd F. An analysis of current analgesic preferences for endodontic pain management. J Endod 2006;32:1146-54.

19. Trowbridge $H$, Emling R. Chemical mediators of the vascular response. In: Trowbridge H, Emling R (Eds). Inflammation: A review of the process (5th ed). Chicago: Q uintessence Publishing Co 1997:33.

20. Wynn R, M eiller T, Crossley H. Drug information handbook for dentistry (9th ed). Hudson: Lexi-Comp 2003:356.

21. A verbach $M, K$ atzper $M$. B aseline pain and response to analgesic medication in the postsurgery dental pain model. J Clin Pharmacol 2000;40:133-37.

22. Dionne R. Suppression of dental pain by the preoperative administration of flubiprofen. J A m M ed A ssoc 1986;80(Suppl $3 A): 41-49$

23. Dionne R, Campbell R, Cooper S, Hall D, Buckingham B. Suppression of postoperative pain by preoperative administration of ibuprofen in comparison to placebo, acetaminophen and acetaminophen plus codeine. J Clin Pharmacol 1983;23:37-43.

24. M odaresi J, Dianat $O, M$ ozayeni M A. The efficacy comparison of ibuprofen, acetaminophen-codeine, and placebo premedication therapy on the depth of anaesthesia during treatment of inflamed teeth. Oral Surg Oral M ed Oral Pathol Oral Radiol Endodontol 2006;102:399-403

25. A ggarwal V, Singla M, Debipada K. Comparative evaluation of effect of preoperative oral medication of ibuprofen and ketorolac on anesthetic efficacy of inferior alveolar nerve block with lidocaine in patients with irreversible pulpitis: A prospective, double-blind, randomized clinical trial. J Endod 2010;36:375-78.

26. Bakshi R, Jacobs LD, L ehnert S, Picha B, R euther J. A double blind, placebo controlled trial comparing the analgesic efficacy of two formulations of diclofenac in postoperative dental pain. Current Therapeutic Res 1992;52:435-42.

27. Naushaba Q. Musculo-skeletal and joint disorders: Comprehensive handbook of drug prescription (6th ed). Physician's Pakistan D rug M anual: Q uaterly M edical Channel Karachi 2006:720.

28. Wiseman EH, Chang YH, Lombardino JG. A novel antiinflammatory agent. A rzneimittelforschung 1976;26:1300-03.

29. Carty TJ , E skra J D, L ombardino J G , H offman W W. Piroxicam, a potent inhibitor of prostaglandin production in cell culture. Structure-activity study, Prostaglandins 1980;19:51-59.

30. Thun M J, Henley SJ , Patrono C. N onsteroidal anti-inflammatory drugs as anticancer agents: mechanistic, pharmacologic and clinical issues. J N atl Cancer Inst 2002;94: 252-66.

31. Berg J, Fellier H, Christoph T, Grarup J, Stimmeder D. The analgesic NSA ID lornoxicam inhibits cyclooxygenase (COX)$1 /-2$, inducible nitric oxide synthase (iNOS), and the formation of interleukin (IL)-6 in vitro. Inflammation Res 1999;48: 369-79.

32. Hall PE, Derry S, Moore RA, M CQuay HJ. Single dose oral lornoxicam for acute postoperative pain in adults. Cochrane Database of Syst Rev 2009 Oct;4:CD 007441.

33. Fuss Z, Trow bridge H, B ender I, Rick off B, Sorin S. A ssessment of reliability of electric and thermal pulp testing agents. J Endod $1986 ; 12: 301-05$ 
34. Petersson K, Soderstrom C, K iani-A naraki M , Levy G. Evaluation of the ability of thermal and el ectric tests to register pulp vitality. Endod Dent Traumotol 1999;15: 127-31.

\section{ABOUT THE AUTHORS}

\section{Aisha Wali (Corresponding Author)}

Senior Lecturer, Department of Operative Dentistry, Baqai Dental College, Sindh, Pakistan, e-mail: aishawali@ hotmail.com

\section{Talha Mufeed Siddiqui}

A ssociate Professor, D epartment of O perative Dentistry, B aqai Dental College, Sindh, Pakistan

\section{Nauman Qamar}

Lecturer, Department of O perative Dentistry, Baqai Dental College Sindh, Pakistan

\section{Rabia Khan}

House Surgeon, Department of Operative Dentistry, Baqai Dental College, Sindh, Pakistan

\section{Nausheen Jawaid}

House Surgeon, Department of Operative Dentistry, Baqai Dental College, Sindh, Pakistan 